\title{
Política de comércio exterior e desenvolvimento: a experiência brasileira
}

\author{
AMADO LUIZ CERVO*
}

\section{Introdução}

A política de comércio exterior do Brasil envolveu historicamente um grande debate nacional. Governo e lideranças sociais a ela vincularam as possibilidades do desenvolvimento econômico, desde as origens, na primeira metade do século XIX. Em três períodos ela foi atrelada a diferentes paradigmas de inserção internacional: o liberal conservador do século XIX, que se estendeu até os anos 1930; o do Estado desenvolvimentista que vigorou desde então até 1989; e o novo paradigma de inserção liberal em formação nos anos noventa. O presente estudo se propõe recuperar as tendências fundamentais da primeira fase para inclinar-se longamente sobre as duas últimas com a intenção de compreender as atitudes e as definições do governo e da sociedade diante das políticas de comércio exterior bem como os impactos sócio-econômicos que elas exerceram nas últimas décadas.

\section{O período do Nacional-desenvolvimentismo (1930-1990)}

\subsection{Política de comércio exterior, multilateralismo e bilateralismo. A lei de 1899, liberalismo e comércio compensado nos anos trinta, a criação do sistema de Bretton Woods. Impacto da criação do MCE e OPA.}

Até o regime de licenciamento das importações, que seria desde 1947 o instrumento destinado a acionar o modelo substitutivo de importações, não houve no Brasil continuidade de política comercial. Os regimes aduaneiros eram fixados de forma empírica, o que não valia dizer irracional, porquanto eram determinados por razões que ora ponderavam um, ora outro elemento de cálculo. Buscava-se 
expandir as exportações, uma tendência favorável ao regime de livre comércio, ou defender a indústria nacional, outra tendência favorável à proteção do mercado interno. Buscava-se ora o tratamento de nação mais favorecida, ora a obtenção de tarifas reduzidas ou de direitos acordados, ora a reciprocidade de tratamento, ora o tratamento privilegiado, ora preencher as necessidades do tesouro, ora, enfim, o simples interesse do consumidor interno.

À diferença dos Estados Unidos, onde o regime aduaneiro foi posto desde a independência a serviço da industrialização interna, com acentuação dessa tendência a partir da Guerra de Secessão, e onde a política de comércio exterior integrou-se ao ideário dos partidos, sendo o republicano fortemente protecionista e o democrata propenso ao livre comércio, o Brasil conheceu fortes oscilações entre o protecionismo e o livre comércio e nunca converteu a política de comércio exterior em bandeira partidária. A percepção macroeconômica, ou seja, a consciência de que a política de comércio exterior condiciona as estruturas econômicas - mantendoas arcaicas, primárias, agrícolas, ou desencadeando a modernização industrial ocorreu cedo no Brasil, nos anos 1840. À essa época, uma forte reação diante do regime de baixas tarifas fixadas à época da independência, sob pressão do imperialismo das portas abertas com que a Grã-Bretanha e outros países capitalistas impuseram o livre comércio para fora, fez aflorar no Brasil, uma vez por todas, o pensamento protecionista, segundo o qual ao Estado convinha tanto fomentar a expansão da economia agrícola quanto fazer desabrochar as indústrias.

Desde a tarifa protetora de 1844, as oscilações entre o livre comércio e o protecionismo fariam o regime aduaneiro do Brasil alternar no curto prazo entre o protecionismo, por vezes exacerbado, e o livre comércio que era reivindicado pelos interesses da agroexportação. A própria República Velha (1889-1930), considerada coesa na implementação da "diplomacia da agroexportação" conheceu essas oscilações. A tarifa Rui Barbosa de 1890, de caráter fortemente protecionista para acabar com o exclusivismo agrícola da economia, foi sucessivamente modificada pelo Congresso e acabou sendo substituída em 1896 pela tarifa Rodrigues Alves. Esta, por sua vez, seria substituída no ano seguinte pela tarifa Bernardino de Campos, que significou um recuo do protecionismo. Uma certa ordem na política de comércio exterior adviria com a lei aduaneira de 22 de novembro de 1899 (Tarifa Joaquim Murtinho) que se prolongaria até os anos trinta do século XX com pequenas alterações. Introduzia-se a tarifa dupla, mínima e máxima, que permitia ao Executivo taxar fortemente as importações de países que não favorecessem a entrada dos produtos brasileiros. Os Estados Unidos beneficiaram-se enormemente com esse mecanismo porquanto o café lá entrava livre de direitos, ao passo que a Europa teve que negociar novos convênios (França, Itália) para obter as tarifas mínimas. Mas a redução negociada com Europa foi pequena e, por essa razão, ceder-seiam preferências para entrada de produtos norte-americanos nos portos do Brasil e um novo tratado em 1923, após a promulgação nos Estados Unidos da Emergency 
Tariff de 1922, até então uma das mais protecionistas dentre as suas leis aduaneiras. Em 1923, todos os produtos estrangeiros ficaram em pé de igualdade, sujeitos à tarifa mínima, enquanto se buscavam tratados de reciprocidade, com a cláusula de nação mais favorecida ${ }^{1}$.

A ascensão de Getúlio Vargas ao poder após o triunfo da Revolução de 1930 representou novo momento para o país. Externamente, a crise dos preços e a depressão capitalista representavam desafios novos para os formuladores de política comercial e, internamente, a determinação de promover como opção política o crescimento das indústrias resultou de percepções de interesses da sociedade. Era indispensável relançar o comércio exterior para alcançar resultados de modernização interna, daí o cuidado e a preocupação que o governo revelou a seu respeito.

O decreto de 8 de setembro de 1931 pôs termo à lei de 1900, introduzindo novo regime tarifário. Todas as nações eram convidadas a firmar acordos com cláusula de nação mais favorecida e dispositivos práticos para regular o comércio bilateral. Universalismo e bilateralismo eram, portanto, pragmaticamente vinculados na nova política de comércio exterior. Entre 1931 e 1933, 31 acordos dessa natureza foram firmados com diferentes países e outros mais o seriam até que, em dezembro de 1935, todos os acordos com cláusula ilimitada de nação mais favorecida foram denunciados de uma só vez. Em maio de 1936, em sua mensagem ao Congresso, Vargas forneceu as razões para a ruptura e a necessidade de nova política de comércio exterior: os acordos anteriores haviam cessado de produzir os efeitos esperados, porque poderosos óbices foram introduzidos, que neutralizavam seus efeitos, tais como tarifas proibitivas, contingenciamento de importações, exigência de compensações, não-pagamento.

A disposição, a partir de 1935, quando se rompeu com o caráter universalista, era a de não mais ostentar uma política de comércio exterior, ao menos ela deixaria de ser referida no discurso do governo. Com senso realista e pragmático, o governo agia e reagia ante as circunstâncias e as tendências do comércio internacional. Essa flexibilidade convinha para evitar pressões sobretudo norte-americanas e para poder manobrar entre os blocos antagônicos que dividiam o mundo no pré-guerra. Aos Estados Unidos Vargas cederia em 1935 um tratado liberal, com cláusula de nação mais favorecida, levantando protestos generalizados da opinião que o considerava prejudicial à expansão da indústria e lesivo ao interesse nacional. A resposta a esse clamor viria em 1936, por meio do tratado com a Alemanha, e de outro com o da Itália, chamados de comércio compensado, porquanto intercambiavam produtos que eram solicitados de lado a lado e incluídos em listas flexíveis e compensáveis. Por essa via, os interesses tanto da agroexportação quanto da burguesia urbana nacional eram atendidos, além de estarem os militares satisfeitos com o fornecimento de equipamentos para as Forças Armadas. O comércio compensado, bilateral e antiliberal, revelou excelente desempenho, porquanto elevou a Alemanha em 1938 à posição de primeiro 
fornecedor externo do país. O descontentamento dos exportadores norte-americanos traduziu-se em pressões diplomáticas que seriam convertidas por Vargas em poder de barganha para negociação de vantagens concretas e compartilhadas, já no contexto de preparação para a guerra mundial. Essas circunstâncias permitiram ao país excelentes resultados junto aos Estados Unidos em termos de créditos para exportações, condições especiais de entrada e financiamentos para a indústria nacional, de que foi maior exemplo a construção da usina siderúrgica de Volta Redonda.

A lição que se pôde auferir dos conturbados anos trinta e do contexto de guerra para implementar uma política de comércio exterior destinada a estimular os negócios, a buscar o equilíbrio das contas externas e a promover mudanças estruturais na economia nacional rumo à industrialização era a de que não convinha uma diretriz permanente mas sim operar em jogo escondido. Bilateralismo, liberalismo e universalismo caíram no descrédito. Como afirmava Vargas em mensagem ao Congresso Nacional, ante as práticas dos outros só era possível ao país "manter constante atividade e vigilância" caso pretendesse "defender os interesses nacionais". O pragmatismo dos meios sobrepunha-se ao conselho dos princípios $^{2}$.

O governo de Gaspar Dutra, entre 1945 e 1950, revelaria mais uma vez que a opção por uma determinada doutrina não convém à condução da política de comércio exterior. Determinado inicialmente a apoiar as concepções norteamericanas de uma ordem econômica internacional fundada nos parâmetros do liberalismo universal e ilimitado - do comércio internacional, dos capitais, das empresas e das finanças - prestou a esse país um apoio valioso em razão de importante papel que a contribuição de guerra ao lado dos aliados lhe facultou na criação dos órgãos internacionais - ONU e sistema de Bretton Woods. A crença de que o liberalismo atrairia investimentos moldou também os regimes tarifário e cambial. A ilusão fez-se perceber logo. Em 1947, implantava-se um sistema de controle de importações para fazer face ao déficit do comércio exterior e a ele agregava-se, em 1949, novo regime de câmbio com licença prévia. Foi, portanto, o próprio governo Dutra que criou os mecanismos que seriam utilizados pelos governos posteriores para acionar o Nacional-desenvolvimentismo consoante o modelo de substituição de importações. A política de comércio exterior tornava-se assim mais introspectiva e autônoma, apesar da conclusão de acordos bilaterais de comércio com inúmeros países. O controle do câmbio e o regime de licenças para as importações condicionavam os dispositivos dos tratados bilaterais ${ }^{3}$.

O retorno de Vargas ao poder em 1951 significava uma injeção de nacionalismo econômico na política exterior. A conjuntura não lhe era favorável, estando o parceiro principal, os Estados Unidos, sob orientação dos governos Truman e Eisenhover. Para estes, e para os órgãos internacionais como o Banco Mundial e o Fundo Monetário Internacional, a intervenção do Estado no controle do comércio 
e das finanças era nociva, a não ser que se fizesse para sanear as finanças públicas por medidas de ortodoxia liberal e para desobstruir os fluxos econômicos com o exterior mediante a adoção dos cânones do mercado. Vargas revidava com o discurso dos egoísmos dos grandes, da competição econômica e das necessidades do desenvolvimento. Embora não estivesse disposto a fazer concessões gratuitas, seu nacionalismo não podia ser qualificado de confrontacionista. Ao contrário, buscava por todos os modos a cooperação para o desenvolvimento, sobretudo com o parceiro principal, os Estados Unidos, cedendo o quanto convinha em termos de abertura de mercado, de facilidades para investimentos e para remessa de lucros. Segundo a palavra de seu Ministro das Relações Exteriores, a época caracterizase pela "elevação da idéia de defesa econômica em fator central da política exterior dos povos”; e o significado desse diagnóstico para o Brasil era claro: "nossa política exterior não perde de vista o aparelhamento econômico e industrial do país"4 .

Em 1957, discursando na XII Sessão Ordinária da Assembléia Geral da ONU, Oswaldo Aranha expressava nesse foro pela primeira vez uma nova tendência do pensamento diplomático brasileiro, destinada a desenvolver-se posteriormente. Deixava clara a percepção dos brasileiros de como os Estados Unidos no pósguerra haviam negligenciado a América Latina, investindo esforços e capitais na reconstrução da Europa, um empreendimento aliás bem sucedido. Reconhecia que a América Latina frustrou-se igualmente ao apoiar em Bretton Woods a criação das agências de fomento: o BIRD cumpria apenas a tarefa da reconstrução e ignorava a do desenvolvimento dos povos, sua segunda razão de ser; o FMI desviarase de seu objetivo original que era dirimir as dificuldades de balanços de pagamentos. Aranha conclamava as Nações Unidas a empreenderem "uma participação mais ativa no encaminhamento da solução dos problemas de desenvolvimento econômico". Introduzia, pois, a visão Norte-Sul dos problemas internacionais em plena vigência da política norte-americana do containment e da massive retaliation. Acreditava corresponder a todo pensamento latino-americano essa nova visão do mundo, mas traduzia sua fé nos organismos internacionais e no multilateralismo como agentes e método indutores de mudanças: "Não somos, porém, um bloco e nem queremos ser. As Repúblicas Americanas não se guiam por aspirações puramente continentais" ${ }^{\circ}$.

O pensamento multilateralista brasileiro reagiu à criação do Mercado Comum Europeu, denunciando seus prejuízos ao país em termos de comércio e investimentos tanto na Assembléia Geral da ONU quanto junto ao GATT. A associação do bloco à economia dos territórios coloniais era vista como nova versão do imperialismo, origem de "novas distorções permanentes nas relações econômicas internacionais” nas palavras do delegado brasileiro, José Joffily, à Assembléia da ONU de 1958. Junto ao GATT, a representação brasileira protestou com veemência contra as discriminações tarifárias e não-tarifárias de que seriam vítimas os países da América Latina, alardeando o atentado que se cometia contra os princípios 
originais do órgão de liberalização e de promoção da competitividade do comércio internacional ${ }^{6}$.

Embora não fosse uma reação direta à integração européia e europeucolonial, que eram vistas como uma ameaça para as exportações brasileiras, a Operação Pan-Americana encaminhada pelo Presidente Juscelino Kubitschek em 1958 orientava a política exterior do Brasil para a América Latina mediante um programa de esforços integrados de todo o continente para realização de projetos de desenvolvimento. Era o início do multilateralismo regional. $\mathrm{Na}$ realidade, essa orientação da política exterior era compreendida no contexto de inúmeros fatores: a decepção pela negligência dos Estados Unidos com a América Latina estava a reclamar uma tomada de consciência e uma nova atitude; o reordenamento das relações internacionais para enfrentar os problemas do atraso e do desenvolvimento dos povos impunha-se como oportuno na percepção dos brasileiros, após a reconstrução européia e a estabilização política internacional; a criação de uma união aduaneira na Europa e desta com suas colônias reclamava a união das Américas; o pensamento cepalino e o desenvolvimentismo dinâmico do Brasil estavam a exigir volume crescente de cooperação internacional. Entende-se, pois, o pensamento do ideólogo da OPA, Embaixador Augusto Frederico Schmidt: “A Operação Pan-Americana visa a reforçar o conteúdo econômico do Pan-Americanismo, mediante a adoção de um conjunto de medidas enérgicas e coordenadas, suscetíveis de remover os obstáculos ao desenvolvimento dos países da América Latina, cujas economias necessitam de vigoroso impulso para que ultrapassem o estado de atraso em que se encontram e ingressem numa era de industrialização, aproveitamento máximo dos recursos naturais e ativo intercâmbio"”.

\subsection{As experiências de integração entre 1960 e 1986. CEPAL, ALALC, ALADI}

Julgou-se muitas vezes que o modelo cepalino de substituição de importações teria sido responsável pelo malogro do multilateralismo continental, especialmente o da Associação Latino-Americana de Livre Comércio (ALALC), criada em 1960. Uma revisão recente do legado conceitual da CEPAL lança dúvidas sobre essa interpretação, visto que a prática daquele modelo correspondia a uma racionalização do processo de proteção e expansão industrial sem conflito aberto com a negociação comercial ou com a integração regional. Tampouco pode-se afirmar categoricamente que o modelo substitutivo respondia ao exacerbado protecionismo latino-americano que o precedeu, porque sua filosofia era a de promover mudanças estruturais na economia da região, uma necessidade histórica que o processo de integração recente contempla, quando põe ênfase na competitividade e na apropriação de tecnologias avançadas. De todo modo, 
percebe-se que o discurso liberal inerente ao pensamento latino-americano não apresentava e não mais apresentaria, dos anos cinqüenta aos oitenta, coerência com políticas comerciais que eram marcadamente protecionistas ${ }^{8}$.

Os anseios de integração regional foram inicialmente tomados por utópicos pela diplomacia brasileira. Em documento de 1964, Vasco Leitão da Cunha, Ministro das Relações Exteriores, afirmava claramente que a integração estava condicionada à construção de meios de comunicação regional, como vias rodoviárias, fluviais, marítimas e aéreas. Apesar disso, o discurso diplomático prosseguiria nos anos a seguir dando apoio explícito à ALALC. Mas era incoerente ao reconhecer seu bom funcionamento e ao mesmo tempo afirmar que a integração haveria de se fazer de forma gradual, criando-se previamente condições físicas adequadas ${ }^{9}$. O amadurecimento dessa última percepção levaria as diplomacias dos países da Bacia do Prata a firmar em 1969 o Tratado da Bacia do Prata, destinado a "promover o desenvolvimento harmônico e a integração física da Bacia do Prata e de suas áreas de influência”" ${ }^{\text {. A iniciativa }}$ produziria resultados concretos, visto que 180 resoluções haviam sido aprovadas pelos chanceleres até 1981, mas não foi em seu seio que teve equacionamento o contencioso acerca do aproveitamento dos rios da região.

Nas décadas de sessenta e setenta, a diplomacia brasileira empenhouse no sentido, não de modificar o modelo substitutivo de importações mas no de provocar o modelo complementar, o substitutivo de exportações. Com efeito, o vasto parque industrial já implantado no Brasil havia cumprido com sua função original e pressionava por mercados externos de manufaturados. Os países avançados cerceavam a realização desse objetivo mediante os contingenciamentos que se tornaram regra na Europa e nos Estados Unidos. Por esta razão, a diplomacia brasileira reviu sua política africana e buscou penetrar o mercado da África através dos novos Estados independentes. Quanto à América Latina, tentou converter a ALALC em via de escoamento desses manufaturados à região. Em 1971, pela segunda vez em dez anos de ALALC, o Embaixador Maury Gurgel Valente reivindicava em sessão do Comitê Executivo Permanente preferência na zona para os produtos industrializados do Brasil, sem qualquer êxito ${ }^{11}$. A ALALC caía em descrédito e o termo integração passaria a ter uma conotação mais política que comercial, aliás passaria freqüentemente a expressar toda e qualquer iniciativa em andamento na América Latina - diplomática, política, estratégica, econômica, cultural etc. - o que evidenciava a desqualificação do conceito. O declínio do termo e do conceito integração ocorreria na linguagem diplomática brasileira em tendência contrária à ascensão e valoração do termo cooperação, que abrigava tanto o desempenho do multilateralismo, considerado sofrível, quanto do bilateralismo, crescentemente promissor.

No início dos anos oitenta, a percepção de que a América Latina era pouco relevante para a estratégia de inserção internacional do país consoante o 
paradigma do Nacional-desenvolvimentismo direcionava o discurso diplomático para a esfera vazia do entendimento e para parcas oportunidades concretas de negócios relevantes. Com efeito, as três fases a galgar para atingir um desenvolvimento pleno requeriam da política exterior o preenchimento de requisitos e o fornecimento de insumos que não eram encontrados nos esquemas de relações regionais: consolidar e dar sustento ao parque industrial; prover a economia de matérias-primas básicas, mormente energia; e adquirir e desenvolver tecnologias avançadas. O mercado dos países da região, protegido pelas políticas substitutivas, via com suspeita as preferências procuradas pelo Brasil que queria substituir como fornecedor aos países industrializados. Bolívia e Colômbia não davam andamento aos projetos de cooperação na área energética e de mineração. A Argentina procurava obstruir essa cooperação substantiva e alimentava a querela acerca do aproveitamento dos rios. Apenas o Paraguai dava garantias à execução de um projeto importante, a hidrelétrica de Itaipu. Nessas condições, a diplomacia buscava manter as aparências de uma região unida: "Estimular o diálogo entre os nossos vizinhos...levar adiante os ideais de cooperação regional”, eram expressões que reproduziam um discurso sem conteúdo, a menos que preparasse uma fase de efetiva cooperação regional ${ }^{12}$.

\subsection{A pregação do multilateralismo: GATT, ONU, GRUPO dos 77 e outros}

Enquanto conformava-se com o malogro do multilateralismo regional, durante três décadas, entre 1960 e 1990, a diplomacia brasileira veiculou insistente discurso multilateralista no sistema ONU, incluindo a UNCTAD, no Grupo dos 77, no GATT e em outros organismos internacionais ${ }^{13}$. Os impulsos que alimentavam a pregação multilateralista e liberal da diplomacia eram: a) a convicção de que a expansão das exportações era elemento estratégico para acelerar o desenvolvimento; b) a constatação de que os países avançados erigiam crescentes obstáculos à penetração dos produtos primários e manufaturados oriundos do Terceiro Mundo; c) a reivindicação de tratamento preferencial sem contrapartida a ser dado às economias em desenvolvimento pelos países do Primeiro Mundo; d) a condição de global trader que era ostentada como perfil do comércio exterior que convinha ao país. A todos esses impulsos assistia por um certo tempo uma ingênua visão de ordem internacional a ser construída pela ação dos órgãos multilaterais e posta a serviço do desenvolvimento dos povos atrasados. Essa pregação passou nesse período pelas fases de entusiasmo, ceticismo e descrença com que a diplomacia se movimentava nos órgãos multilaterais, porém sem nunca desistir ou arredar pé. Com efeito, a presença brasileira nesses órgãos situava o país entre os quatro ou cinco países de maior representação.

A perversidade do sistema internacional era denunciada em razão da inoperância de resoluções aprovadas com o fim de promover o desenvolvimento, 
em razão da articulação dos países avançados para neutralizar os ganhos concedidos através do sistema geral de preferência e da autorização de proteger indústrias nascentes no Terceiro Mundo, em razão das políticas nacionais de comércio exterior que revidavam às reivindicações dos países menos desenvolvidos, em razão enfim da conduta de órgãos como GATT, FMI, BIRD que contemplavam via de regra apenas os interesses dos países centrais. Tudo isso levaria a minar, enfim, a fé no multilateralismo como via de promoção dos interesses do desenvolvimento nacional, como reconhecia o Presidente João Figueiredo ao abrir a XXXVII sessão ordinária da ONU em 1982: "Têm sido infrutíferos os esforços do Terceiro Mundo no sentido de modificar - em instituições como o FMI, o Banco Mundial e o GATT, entre outras - quadros normativos, estruturas de decisão e regras operacionais discriminatórias" ${ }^{14}$.

A percepção de que o sistema internacional obedecia a regras adversas ao mundo em desenvolvimento converteu-se desde os anos sessenta em determinação de buscar a articulação tanto com o Terceiro Mundo quanto com o Primeiro e de engendrar as negociações Norte-Sul com o objetivo de modificar a ordem vigente. Em meados dos anos oitenta, o balanço desses esforços produzia como resultado concreto a perda de credibilidade no multilateralismo como instrumento eficaz para reformar a ordem existente: "Sucedem - afirmava o Chanceler Ramiro Saraiva Guerreiro em 1984 - os episódios de resistências por parte de países desenvolvidos à ação concertada, lembre-se da falta de resultados de Cancún, a obstrução ao lançamento das Negociações Globais, o fracasso da última reunião da UNCTAD, o descumprimento dos princípios e compromissos do GATT"15. Essa crítica generalizada persistiria como elemento central do discurso diplomático brasileiro até o fim da década dos oitenta: “A chamada crise do multilateralismo compromete o esforço de regulamentação jurídica da vida internacional e abala os alicerces da cooperação entre os Estados”16.

\subsection{A diplomacia e o MERCOSUL, das origens ao Tratado de 1991}

Conduzida pelo paradigma do Nacional-desenvolvimentismo e pelo pragmatismo de meios, a política exterior do Brasil não haveria de acalmar-se com as lamentações acerca do funcionamento adverso da ordem internacional e do malogro geral do multilateralismo e com a constatação de que o esforço de integração latino-americana tampouco produzia resultados. Novas oportunidades eram procuradas, e inventadas se necessário. Os presidentes da Argentina, Raúl Alfonsín, e do Brasil, José Sarney, aproveitando-se do bom entendimento em que se assentavam as relações bilaterais, desencadeariam em meados dos anos oitenta, como reação construtiva ao sistema internacional e como resposta de suas políticas exteriores, uma nova modalidade de integração regional.

Embora o Itamaraty fizesse uso do termo integração para qualificar as ações desenvolvidas no seio de órgãos regionais como a ALADI, o SELA, a 
OLADE, o Consenso de Cartagena ${ }^{17}$, o movimento de sua diplomacia junto aos países do Cone Sul destinava-se a inaugurar uma experiência diferente de integração, dadas as causalidades que a haviam inspirado: "No Brasil - dizia o Chanceler Abreu Sodré em 1986 - estamos firmemente, irreversivelmente comprometidos com a causa da integração econômica da América Latina. Há muito que essa integração tem sido exigida, mas nunca antes como agora criaram-se as condições adequadas para o surgimento de uma autêntica vontade política para aprofundála"18.

Com efeito, esse novo processo era claramente visto como uma saída para o impasse do multilateralismo e das tentativas anteriores de integração latinoamericanas. Brasil e Argentina dispunham-se a elevar substancialmente o volume do comércio, a deslanchar a cooperação econômica, mormente a complementação industrial, e a desenvolver conjuntamente tecnologias em setores estratégicos da economia ${ }^{19}$. Ao inaugurar essa nova experiência, impunha-se a necessidade de evitar o discurso sonhador e de firmar o realismo da ação. O Comunicado Conjunto das chancelarias do Brasil e da Argentina evidenciava a 21 de julho de 1986 o caráter cauteloso e firme que haveria de condicionar os passos deste novo processo de integração: crescimento econômico dos dois; comércio dinâmico e equilibrado; ampla cooperação cultural, científica e tecnológica; gradualismo e flexibilidade dos mecanismos para haver adaptação do sistema produtivo; preferências aos produtores industriais e agrícolas da região; realismo das propostas para evitar a letra morta dos atos; aperfeiçoamento da infra-estrutura física requerida pela integração; função reguladora e jurídica do Estado conjugada com função dinâmica do empresariado; integração empresarial com base no mercado ampliado ${ }^{20}$.

A Ata para Integração Brasileiro-Argentina juntamente com os 12 protocolos firmados a 29 de julho de 1986 pelos chanceleres Abreu Sodré e Dante Caputo definiram a filosofia da nova integração. O processo guiar-se-ia por três diretrizes básicas: a) enquadramento com o pensamento nacional-desenvolvimentista que havia animado as políticas exteriores dos dois países nas últimas décadas e que desde aquele momento acoplavam-se para robustecer-se; b) evolução gradual e flexível, com atos e mecanismos a serem extraídos de forma seletiva de um conjunto de decisões estratégicas que comporiam o permanente processo negociador; c) expansão em leque pela América Latina, desde o eixo original BrasilArgentina ${ }^{21}$.

O sucesso que originalmente se vislumbrava para a iniciativa de integração no Cone Sul, a ser interpretada como reação concreta diante da existência de obstáculos na ordem internacional, não modificou as diretrizes da política exterior do Brasil até o fim dos anos oitenta. Cinco pontos norteavam a conduta diplomática às vésperas da virada liberal dos anos noventa, pontos estes que correspondiam ao acumulado das últimas décadas: a) o desempenho universalista que impedia se priorizassem regiões ou conceitos na escolha dos objetivos a serem alcançados; b) 
a apresentação de propostas circunstanciais para robustecer o multilateralismo e revigorar seus órgãos quando definhavam; c) a subordinação das iniciativas multilaterais e bilaterais externas ao propósito de preencher requisitos de desenvolvimento; d) a eleição do desenvolvimento tecnológico avançado como terceira etapa do desenvolvimento, após a consolidação do parque industrial e da infra-estrutura produtiva; e) o enquadramento do incipiente processo de integração da América Latina na política brasileira do Nacional-desenvolvimentismo pela via da ampliação do mercado, da participação crescente da região no exterior e de seu fortalecimento nos foros multilaterais ${ }^{22}$.

\section{Globalização e regionalização nos anos noventa}

Os anos noventa presenciaram uma radical transformação do pensamento diplomático brasileiro aplicado às relações econômicas internacionais do Brasil. Essa mudança não produziu, todavia, um consenso linear ao longo da década. Alguns traços caracterizam o novo período em seu conjunto, mas a evolução não se faria sem repercussões sobre a sociedade e sem que suas forças acabassem por reagir. Três tempos curtos marcam o período. Durante o governo de Fernando Collor de Mello, entre 1990 e 1992, procedeu-se à demolição instantânea dos conceitos que haviam alimentado há décadas os impulsos da diplomacia: o Nacionaldesenvolvimentismo e sua carga política e ideológica cederam à vontade de abrir a economia e o mercado de forma irracional e reativa à onda de globalização e neoliberalismo que penetravam de fora. Ao substituí-lo na Presidência, Itamar Franco recuou momentaneamente aos parâmetros anteriores do Estado desenvolvimenista, sem contudo bloquear a consciência da necessidade de se prosseguir com as adaptações aos novos tempos. A ascensão à Presidência da República de Fernando Henrique Cardoso, em 1995, levou à reposição das disposições ideológicas e políticas do primeiro Fernando no seio do Estado, vale dizer ao desprezo pelo projeto nacional de desenvolvimento e à resignação diante da nova divisão do trabalho inerente à forma globalizante do capitalismo, mas seu estilo de diplomacia democrática daria alento a pressões que vinham de segmentos sociais e que acabaram por condicionar o pensamento e o processo decisório.

\section{1 - Liberalismo multilateralista radical: a abertura reativa}

O pensamento que confrontou o Nacional-desenvolvimentismo desde os primeiros dias do governo de Fernando Collor foi o da modernização. Esse pensamento surgiu no embate da campanha eleitoral para as eleições presidenciais do final de 1989, porquanto seu opositor ainda alardeava os parâmetros do discurso anterior, e tomou conta do Estado e da sociedade após a vitória nas urnas. De tipo 
triunfalista e mágico, o discurso da modernização alimentou a expectativa de um salto para frente em termos de qualificação nacional e de inserção internacional “correta e definitiva”, uma espécie de "fuga da periferia"²3. O governo circunscreveu sua doutrina de modernização apenas à implementação prática de duas decisões: a simples abertura de mercado - que agradava a uma classe média consumista - e à privatização de empresas públicas - que interessava a portadores de títulos da dívida interna.

O diagnóstico das dificuldades que a ordem internacional em construção após o término da Guerra Fria oferecia à abertura da economia brasileira fundavase em percepções novas mas também em obstáculos tradicionalmente denunciados: o protecionismo dos ricos e o egoísmo dos megablocos econômicos convertidos em "fortalezas comerciais", a fraqueza do multilateralismo, a retirada da cooperação para o desenvolvimento da agenda internacional. O discurso liberal-modernizador do início dos anos noventa mergulhava na ideologia dependentista: pela via da abertura comercial e econômica, a promoção do desenvolvimento interno era confiada ao estrangeiro que, mediante a transferência de tecnologias e de recursos, elevaria a competitividade do sistema produtivo nacional ao tempo em que o desnacionalizava ${ }^{24}$.

Ao proceder ao balanço de sua gestão, a 13 de abril de 1992, na cerimônia de transmissão do cargo a Celso Lafer, o Chanceler Francisco Rezek reivindicava do exterior o que se praticava no Brasil: "A liberalização do comércio, a abertura da economia e o programa de privatização apoiaram nosso combate às tendências anacrônicas de protecionismo e discriminação e nossa luta por regras que disciplinem o intercâmbio internacional de bens e serviços. Fortaleceram, também, nosso projeto de integração regional que integra mercados sem discriminar contra terceiros.”25. Os dois chanceleres de Fernando Collor, eminentes intelectuais e analistas das relações internacionais, não permitiram a simplificação do pensamento diplomático que certamente agradava ao Presidente. Lafer alude à complexidade do Brasil para indicar a gama de interesses que a política exterior haveria de veicular de forma pragmática, operando entre o multilateralismo e a integração: “O Brasil é um país amplo e complexo. Por isso ele tem interesses globais. Nós não queremos adesões excludentes, mas evidentemente nós temos prioridades, e aqui o conceito com o qual estamos trabalhando é o de parcerias operacionais”26.

A integração, uma liberalização de âmbito regional, é percebida como exercício suplementar ao esforço de liberalização no âmbito global com vistas a estimular o comércio internacional. São todavia as dificuldades e a lentidão do multilateralismo em eliminar entraves ao comércio que induzem uma distorção nos processos de integração com a formação indiscriminada de blocos regionais fechados ${ }^{27}$. Segundo Celso Lafer, o que convém ao Brasil é o triunfo do multilateralismo sobre qualquer outra prática de comércio internacional e todo esforço deve tender à realização desse objetivo. Embora fossem importantes os 
intercâmbios com Estados Unidos, União Européia e Japão, os três pólos dinâmicos da economia mundial, bem como os intercâmbios crescentes no seio do MERCOSUL, o perfil de global trader do Brasil não aconselha concentrar suas relações com um determinado parceiro, como ocorre com México e Canadá no seio do NAFTA. O ideal são parcerias estratégicas operativas, porém múltiplas, enquanto se aguarda o triunfo do multilateralismo universal. Em particular, o processo de integração do Cone Sul, aberto e complementar, deve evitar os riscos de exclusivismos que o NAFTA impôs aos parceiros dos Estados Unidos ${ }^{28}$.

\section{2 - O recuo desenvolvimentista de Itamar Franco}

A reconquista do discurso desenvolvimentista pelo presidente Itamar Franco (fins de 1992 a fins de 1994) trouxe novamente a público o pensamento precursor do processo de integração do Cone Sul, aquele que o subordinava não em primeiro lugar à criação do mercado ampliado mas ao apoio logístico aos sistemas produtivos nacionais num esforço de desenvolvimento sustentado. Essa nuance de pensamento tendia à introspecção na concepção da integração e, para compensar essa introspeç̧ão, o Presidente estimulava a articulação do MERCOSUL com o Chile e a Bolívia, com o Pacto Andino e com os países que integravam a Cooperação Amazônica. Propôs, no âmbito de negociação da ALADI, a criação de uma Área de Livre Comércio Sul-Americana (ALCSA), com o intuito de reforçar a integração regional e de controlar seus mecanismos, subordinando-os ao projeto de desenvolvimento associado sul-americano ${ }^{29}$.

Se o pensamento desenvolvimentista de Itamar afinava-se com seu segundo Chanceler, Celso Amorim, não era claro que houvesse seduzido o primeiro, Fernando Henrique Cardoso, que ocupou a pasta entre 5 de outubro de 1992 e 21 de maio de 1993. Pensador sistêmico e autônomo, de trânsito fácil entre doutrinas antagônicas em nome das circunstâncias, o futuro Presidente da República conformava-se, enquanto Chanceler, com enunciar princípios de política econômica e comercial tradicionalmente aplicados às relações internacionais do país. Punha ênfase no caráter de global trader para situar o MERCOSUL como alternativa de grande utilidade, porém diluída numa estratégia conservadora de comércio exterior que resumia em quatro pontos: a) abertura de novas frentes de comércio; b) busca de maior liberalização dos fluxos comerciais e de maior acesso aos mercados internacionais; c) explorar nichos de oportunidades comerciais junto aos centros dinâmicos do Norte; d) consolidar a projeção das exportações nos mercados regionais e nos países em desenvolvimento ${ }^{30}$.

Os conceitos que acabam por prevalecer no Itamaraty durante o governo de Itamar são os de um multilateralismo ortodoxo e de uma integração inevitável. A menção à integração costumava vir acompanhada de algum atributo restritivo que denotava graus variados de impropriedade. "Os esforços de cooperação política 
e econômica do Brasil - afirma Amorim - não se esgotam na América Latina. De vocação universal, nossa diplomacia tem se empenhado em consolidar e aprofundar os laços que nos unem a países amigos em todos os quadrantes do globo, assim como em desenvolver novas e importantes parcerias políticas e comerciais”. Para evitar precisamente de ter que manifestar repugnância pelo processo de integração do Cone Sul, a diplomacia lançará o conceito de regionalismo aberto. Nele situamse as iniciativas de alargamento do MERCOSUL aos países da América do Sul no âmbito da formação da ALCSA até o ano 2005. Assim mesmo, “o regionalismo aberto deve ser visto como um complemento, não como uma alternativa ao multilateralismo". MERCOSUL e ALCSA são compatíveis com os princípios e propósitos da OMC, ou seja, com o desejado multilateralismo de "regras estáveis e justas”, governando um mercado aberto universal ${ }^{31}$.

A criação de uma área de livre comércio hemisférica (ALCA) é decidida na Cúpula das Américas de Miami, em dezembro de 1994. O pensamento diplomático brasileiro de então reagia com prudência e aversão à idéia, porque parecia, por um lado, poder engolir a autonomia da política nacional de desenvolvimento que se cuidava de implementar no contexto do MERCOSUL e da ALCSA e, por outro, inibir o conveniente multilateralismo ao fomentar a dependência econômica e a parceria comercial exclusiva vis-à-vis dos Estados Unidos. Era preciso avançar gradual e lentamente, para dar tempo às adaptações da economia nacional e do regionalismo aberto: "A área de livre comércio hemisférica - dizia na ocasião Itamar Franco - se construirá com base na convergência e aproximação dos atuais esquemas de integração sub-regional, cuja importância todos reconhecemos. Serão negociações complexas, com enfoque gradualista. Dentro do espírito de regionalismo aberto que nos inspira, atuaremos com plena observância dos compromissos assumidos multilateralmente e sem que se criem barreiras aos parceiros de outras regiões. Favorecemos o reforço de um sistema multilateral de comércio baseado em regras universalmente aplicáveis”32. Por isso mesmo, negociava-se paralelamente, nesse final de 1994, a aproximação entre MERCOSUL e União Européia, que se faria mediante um acordo-quadro de cooperação que previa no futuro uma zona de livre comércio entre os dois agrupamentos regionais.

\section{3 - Adaptação ao capitalismo global e abandono do projeto nacional; pressão social e diplomacia de consenso}

Estando na Presidência da República Fernando Henrique Cardoso e na Chancelaria Luiz Felipe Lampreia desde o início de 1995, o pensamento brasileiro seria conduzido ao mais avançado estádio de adaptação às tendências da ordem internacional dos anos noventa. O país não era mais visto pelos dirigentes brasileiros como um país em desenvolvimento, vale dizer, a política exterior abandonava 
definitivamente o desígnio de preencher requisitos de desenvolvimento interno que lhe fora consignado nos anos trinta e mantido invariavelmente como vetor nas décadas seguintes. O país não tinha nem deveria ter um projeto nacional. A adaptação à era da globalização significava para a inteligência de cúpula da diplomacia brasileira a aceitação de uma situação de interdependência que o capitalismo traçava a partir de seu centro dinâmico e a busca de alguma compensação em recompensa. A abertura do mercado seria cedida sem barganha, as privatizações seriam implementadas sem cuidar do reforço da economia nacional, o sistema financeiro seria posto a serviço de um plano de estabilização monetária, o indivídio seria entregue à própria sorte. Embora essas avaliações críticas ao novo modelo sócio-político fossem feitas, o governo as tinha por desprezíveis. "Brasil e Estados Unidos - assim expressava Fernando Henrique Cardoso suas convicções - partilham os mesmos valores democráticos e os mesmos princípios da economia de mercado. Não como valores abstratos ou fins em si mesmos, mas antes como o melhor caminho para promover o bem-estar e a prosperidade de seus cidadãos"33.

As críticas eram tímidas em 1995-96, estando a oposição política sem condições de influir sobre uma opinião pública favorável ao governo, em razão de benefícios da estabilização monetária e econômica que advinham para a população. Contudo, lideranças sociais e políticas, dirigentes de órgãos e associações de classe, ainda imbuídos do senso nacional que impregnara um combate de décadas pela defesa dos interesses nacionais, lançavam dúvidas sobre as novas concepções de inserção internacional e não se deixavam deprimir com a acusação de saudosistas de esquerda que lhes endereçava o governo. Indícios de desequilíbrios forneciam argumentos crescentes a essas críticas. O comércio exterior revertia a tendência brasileira de grandes superávits e tornava-se deficitário; o país se endividava de forma assustadora; a indústria nacional perdia parte substantiva do mercado interno; o desemprego estrutural aparecia como uma ameaça no horizonte. Diante desses efeitos do novo modelo de inserção neoliberal no mundo - um novo paradigma liberal-global em construção - as pressões sociais tinham que ser ouvidas.

O impulso oriundo da base social harmonizou-se com a disposição congênita ao governo de Fernando Henrique de exercer uma diplomacia democrática. Percebia-se, talvez pela primeira vez na história do país, a conjunção entre a política exterior e a nação, passando aquela a legitimar-se não mais pelo projeto estatal do Nacional-desenvolvimentismo mas pelo reconhecimento das pressões dos diversos segmentos sociais, de modo a definir sua conduta a posteriori. Isso não significa afirmar que essa harmonia não se tenha realizado no passado, mas que ela deixara de ser iniciativa do Estado e passara a espelhar a dinâmica da própria sociedade na origem da conduta diplomática.

A doutrina simplista da globalização com suas implicações reativas sobre o processo decisório - o que era caro ao governo - foi depurada de seu caráter de subserviência às pressões externas na medida em que a sociedade teve condições 
de exercer pressão sobre as decisões. A diplomacia democrática traduzia-se em diplomacia do consenso ao impor novos condicionamentos aos conceitos que regiam o processo decisório nas esferas multilateral, bilateral, da integração e da abertura do mercado. Em certa medida, regredia-se a orientações e objetivos bem como ao método realista e pragmático de movimento que já se haviam transformado em acumulado histórico da diplomacia brasileira e que vinham sendo aperfeiçoados por força das novas circunstâncias internacionais.

O Ministro Lampreia não só reafirmava a necessidade de se diversificar os mercados externos para as exportações, evitando aprofundar em demasia o MERCOSUL e compensando este eixo com a exploração dos mercados dinâmicos do Norte, mas definia com maior clareza o conceito de regionalismo aberto que vinha sendo observado como orientação para a ALADI em seus esforços de integração latino-americana, "a partir de um esquema de múltiplos focos dinâmicos, baseados em movimentos convergentes de aproximação subregional que consideramos - como dizia Lampreia - uma forma de regionalismo aberto”. Avaliava como experiências positivas tanto a consolidação do processo de integração do Cone Sul quanto os progressos alcançados pelo multilateralismo no seio da OMC. Ao Brasil interessava essa convivência harmoniosa do multilateralismo com a integração $0^{34}$.

O tipo de acordo 4+1, com que os membros do MERCOSUL procuravam estabelecer novas parcerias na América (Chile, Bolívia, Grupo Andino etc), era considerado um mecanismo adequado que tendia à criação de uma zona de livre comércio na América do Sul (ALCSA). Os horizontes estavam, todavia, mais distantes: "O processo de integração é um instrumento para participação mais ampla no mercado global...O MERCOSUL tem comprovado que a integração regional favorece a liberalização comercial global”. A integração de forma cada vez mais explícita é considerada como um meio, não como o fim da política. $\mathrm{O}$ desígnio que convinha realizar era um multilateralismo global e aberto ${ }^{35}$.

Embora a lógica do raciocínio tendesse à expansão gradual da integração regional - do MERCOSUL via ALCSA para a ALCA - a advertência de Itamar Franco em 1994 era tida por oportuna durante o governo de Fernando Henrique. O confronto de interesses e a dificuldade de contemplá-los de parte a parte nas negociações com os Estados Unidos eram percepções que vinham dos anos setenta. As pressões sociais após a abertura econômica dos anos noventa no Brasil evidenciavam que o choque de interesses permanecia, cada lado acusando a outra parte de falta de boa vontade em conciliar interesses. Tudo aconselhava prudência, gradualismo, postergação.

Essas idéias vieram a público em fevereiro de 1996, durante a reunião dos vice-ministros de comércio exterior da ALCA que se realizou em Recife. As experiências de integração, segundo sentenciava Lampreia na ocasião, devem guiar-se pelos princípios de equilíbrio, realismo e pragmatismo. AALCA haveria 
de ser produto do consenso a cada passo, não só internacional, dos governos contratantes, mas acima de tudo produto do "consenso nacional emanado de debate abrangente entre todos os setores da sociedade participante". A diplomacia do consenso, nascida do reconhecimento das pressões da sociedade organizada, configurava-se como nova doutrina a nortear as decisões de política de comércio exterior: "A integração não é um projeto entre governos, é um compromisso entre nações... Não é razoável, assim, esperar que o Brasil se disponha a avançar rapidamente em um novo esforço de liberalização comercial, em particular quando essa abertura envolve relações patentementes assimétricas, com parceiros que dispõem de economias bem mais desenvolvidas, sofisticadas e competitivas”. A pressão social condiciona a política comercial nos anos 199697 e, nessas circunstâncias, a ALCA somente teria chances se repousasse sobre os agrupamentos existentes, os quais atendiam satisfatoriamente os requisitos de bem-estar populari ${ }^{36}$.

Durante a III Reunião de ministros responsáveis pelo comércio exterior das Américas, o chamado Fórum das Américas, realizado na cidade de Belo Horizonte em maio de 1997, o ministro Lampreia poria ênfase ainda maior na nova diplomacia do consenso. Fê-lo tanto em seu discurso como na organização de um fórum paralelo de representantes sociais (federações empresariais do comércio, da indústria e da agricultura, sindicatos patronais, sindicatos operários e outras entidades) que vieram evidenciar ao continente e na prática como a sociedade levava suas necessidades ao governo para subsidiar a tomada de decisões. As lideranças sociais não se opunham de princípio à abertura da economia, uma tendência portanto irreversível para todos, mas desejavam controlar os riscos e os efeitos negativos da globalização sobre a produção agrícola, a indústria, o emprego e a renda.

O Itamaraty realizava desse modo o aprimoramento de seus conceitos e dava conteúdo e sentido operativos à diplomacia democrática pela via do consenso entre Estado e nação. O debate em torno da formação de uma zona de livre comércio hemisférica fornecia a oportunidade que se esperava para a definição desses novos parâmetros de pensamento: a) o Brasil mantém um processo aberto e transparente de consulta com todos os setores sociais relevantes e o faz também ao promover a integração hemisférica; b) a ALCA só terá legitimidade se fundada em consensos nacionais de empresários, trabalhadores e consumidores e por isso sua criação deverá conformar-se aos princípios da cautela, do gradualismo e da flexibilidade, sem decisões precipitadas: c) a sociedade revela os interesses nacionais a serem preservados: "Possuímos um vigoroso parque industrial, construído com muito sacrifício e empenho dos brasileiros, e um setor agroindustrial que, sem recorrer a subsídios, honra com sua produtividade e competitividade o potencial do Brasil também como país de vocação agrícola, graças à abundância de terras para lavrar, água, sol e condições climáticas favoráveis”; d) a ALCA, como o 
MERCOSUL, não corresponde à finalidade da decisão política, sendo esta a participação competitiva do Brasil nos fluxos de comércio e inversões internacionais; e) não há causalidade imediata entre eficiência econômica e solução dos problemas sociais brasileiros ${ }^{37}$.

\section{Conclusões}

O pensamento diplomático brasileiro aplicado no século XX às variadas práticas de comércio exterior revelou percepções objetivas, enunciou conceitos e fundou opções políticas.

Percepções objetivas. Dentre as primeiras percepções da diplomacia brasileira quanto às políticas de comércio exterior dos diferentes países registra-se a constatação de que o multilateralismo do comércio internacional - aquele da cláusula de nação mais favorecida até a Segunda Guerra Mundial e das regulações do GATT depois - estabelece princípios que os governos passam rapidamente a burlar por meio de mecanismos de proteção de seus mercados, que os esterilizam. Essa era a consciência que tinha Vargas nos anos trinta, bem como a viva consciência das três últimas décadas, e a explicação para reações pragmáticas. $\mathrm{O}$ protecionismo latino-americano tanto deriva do modelo substitutivo de importações quanto desses condicionamentos externos. Uma segunda constatação da diplomacia brasileira é a da falta de poder de um país emergente nos foros multilaterais, o que conduziu o Brasil a uma política nacionalista introspectiva e depois a uma integração de precaução no MERCOSUL. Uma terceira percepção aflorou diante de três experiências malogradas e corrigidas de pronto de liberalismo radical, sem uma rationale, observadas nos governos de Dutra (1945-50), Castelo Branco (196467) e Fernando Collor (1990-92): experiências liberais radicais não produzem os efeitos decantados por seus doutrinários e provocam danos diversos à economia e à sociedade. Uma última constatação diz respeito ao fato de que o Brasil, como país novo, deve lutar com maiores dificuldades para abrir mercados externos, já que estes encontram-se sob domínio de economias avançadas cujos agentes lá chegaram e estabeleceram antes seus negócios. A esta visão da conjuntura histórica, acrescentou-se a de que o país, em razão de sua complexa e forte base econômica, deve lidar com o mercado global, visto que para toda parcela que o compõe tem algo a vender.

Princípios e conceitos. As percepções objetivas induzem conceitos e princípios normativos. O primeiro dentre eles é precisamente o cuidado em adotar conceitos e princípios, grandes políticas e modelos (bilateralismo, multilateralismo, livre mercado) porque eles não presidem à prática. Realismo atento e uma diplomacia de plantão impõem-se sobre as doutrinas e os modelos de política de comércio exterior. O crescimento industrial e o desenvolvimento econômico foram eleitos como vetores da política de comércio exterior do 
Brasil, dos anos trinta ao final dos anos oitenta. A ideologia globalizante neoliberal imiscuiu-se no governo Collor em 1990, foi contida por Itamar Franco e ressurgiu durante o governo de Cardoso, porém temperada pela conciliação entre Estado e nação, por meio de uma denominada diplomacia de consenso que levava em conta a manifestação de interesses das lideranças sociais. A nova modalidade da diplomacia de consenso representa um passo à frente nas relações entre Estado e nação, estando esta agora na origem dos impulsos políticos e não mais sendo carregada por um super-Estado protetor, como na fase anterior do Nacional-desenvolvimentismo.

Intenções e opções. Duas linhas de política comercial foram traçadas nas últimas décadas. A primeira conduzia ao protecionismo do mercado, sem contrapartida externa, para servir de suporte e fundamento a uma economia agrícola e industrial em formação. As necessidades do desenvolvimento, consoante o pensamento diplomático, assentavam a legitimidade do protecionismo do mercado, que era ostentado sem melindres diante das crítidas de liberais doutrinários antes dos anos noventa e que passou a legitimar-se, embora em novo modelo, com a diplomacia consensual na era da globalização. A segunda perspectiva da política comercial conduzia ao multilateralismo aberto do mercado mundial. Essa foi a luta travada pelo Brasil nos órgãos multilaterais que regulamentavam o comércio internacional no pós-guerra e a ela subordinou-se o entendimento acerca dos processos históricos de formação de blocos econômicos. Estes são, em princípio, nocivos às regras estáveis e justas do comércio internacional. O pragmatismo não permite, todavia, ao país furtar-se de utilizar a integração como instrumento de defesa e promoção do comércio exterior e até mesmo como via de fato de abertura gradual e flexível dos mercados, até que se realize o ideal do multilateralismo aberto em escala global.

Setembro de 1997

\section{Notas}

1 Cf. Affonso de T. B. de MELLO, Politica Commercial do Brasil, Rio de Janeiro: Tipografia do Departamento Nacional de Estatistica, 1933.

2 Mensagem ao Congresso Nacional, 3 de maio de 1937: Ministério das Relações Exteriores, Relatório, 1936, Anexo A, p. 3-9. Cf. Amado Luiz CERVO e Clodoaldo BUENO, História da política exterior do Brasil, São Paulo: Ática, 1992, p. 214-244.

3 Cf. Sergio Besserman VIANNA, A política econômica no segundo governo Vargas (19511954), Rio de Janeiro: BNDES, 1987.

4 Exposição do Ministro das Relações Exteriores ao Presidente da República, Ministério das Relações Exteriores, Relatório, 1951, p. 5-16. 
5 Oswaldo Aranha, discurso, XII sessão da ONU, 1957, in: Ministério das Relações Exteriores, A palavra do Brasil nas Nações Unidas, 1946-1995, Brasília: FUNAG, 1995, p. 109-112. Clodoaldo BUENO, "Integração ou desintegração? A diplomacia brasileira e a formação do Mercado Comum Europeu”, trabalho apresentado do XVII Encontro Anual da ANPOCS, 1993 (originais cedidos pelo autor). Cf. Relatório, op. cit, 1957, p. 7-10.

Discurso na XIV Sessão ordinária da ONU, 1959, Palavra..., op. cit. p. 124. Cf. Alexandra de M. e SILVA, A política externa de JK: Operação Pan-Americana, Rio de Janeiro: Fundação Getúlio Vargas, 1992.

8 Gabriel PORCILE, “Integração econômica da América Latina: notas sobre o legado teórico da Cepal”, Revista Brasileira de Política Internacional, 36(1): 134-142, 1993.

9 Relatório, op. cit., 1964, p. 19.

10 Ministério das Relações Exteriores, XIII Reunião de Chanceleres dos Países da Bacia do Prata, Brasília: 1982, p. 17.

11 Discurso no encerramento da sessão, em 15 de março de 1971: Ministério das Relações Exteriores, Documentos de política externa, v. V, p. 25-26.

12 Ramiro Saraiva Guerreiro, discurso na XXXVI Sessão Ordinária da ONU, 1981, A palavra..., op. cit., p. 389. Cf. Amado Luiz CERVO e Clodoaldo BUENO, História da política exterior do Brasil, São Paulo: Ática, 1992.

13 Cf. as publicações seriadas da Chancelaria brasileira referidas acima, que publicam os pronunciamentos dos delegados brasileiros junto a estes órgãos, prestam contas ao governo do desempenho da diplomacia e agregam inúmeros outros documentos.

14 A palavra..., op. cit. p. 403.

15 Discurso, XXXIX Sessão Ordinária da ONU, 1984, A palavra..., op. cit. p. 429. Ver as páginas 220, 230, 241, 318.

16 Discurso do chanceler Abreu Sodré na ONU, em 1987, A palavra..., op. cit. p. 474. Ver sua exposição à Escola Superior de Guerra: Ministério das Relações Exteriores, Resenha de política exterior do Brasil, $\mathrm{n}^{\circ}$ 49, p. 123, 1986.

17 Ver o texto de Abreu Sodré em A palavra... op. cit, p. 479.

18 Discurso de Abreu Sodré na ONU, 1986, A palavra... op. cit., p. 462.

19 Visita de Olavo Setúbal à Argentina, Resenha...l, no 45: p. 43, 1985.

20 Comunicado Conjunto das Chancelarias do Brasil e da Argentina, 21 de jul. 1986: Resenha..., $\mathrm{n}^{\circ}$ 50, p. 39, 1986.

21 Ver os atos e demais documentos de 1986 nos números 50 e 51 de Resenha de política exterior do Brasil.

22 Exposição do chanceler Abreu Sodré à Escola Superior de Guerra em 28 de julho de 1988: Resenha..., n ${ }^{\circ}$ 58, p. 27-40, 1988.

23 Discurso de Collor durante a cerimônia de formatura do Instituto Rio Branco: Resenha..., $\mathrm{n}^{\circ}$ 65, p. 7-10.

24 Discurso de Collor na Assembéia Geral da ONU, em 24 de setembro de 1990: Resenha..., nº 66, p. 29-36.

25 Resenha..., no 70, p. 91.

26 Celso Lafer, exposição na Reunião de Coordenação Ministerial de 15 de maio de 1992: Resenha..., $\mathrm{n}^{\mathrm{O}}$

27 Discurso de Celso Lafer na XLVII Sessão da ONU, 1992: A palavra..., p. 549.

28 A inserção internacional do Brasil: a gestão do Ministro Celso Lafer no Itamaraty, Brasília: MRE, 1993, p. 140 e 159.

29 Discurso de Itamar Franco na VII Reunião do Conselho do MERCOSUL, Ouro Preto, 17 de dezembro de 1994: Resenha..., nº 75, p. 57-59. Ver p. 19 e 43.

30 Política externa em tempos de mudança; a gestão do Ministro Fernando Henrique Cardoso no Itamaraty; Brasília: MRE, 1994, p. 19 e 52. 
31 Política externa, democracia, desenvolvimento; gestão do Ministro Celso Amorim no Itamaraty, Brasília: MRE, 1995, vários textos, p. 61-62, 94, 101.

32 Resenha..., no 75, p. 51-52.

33 Discurso de Fernando Henrique Cardoso no National Press Club, Wsahington, 21 abr. 1995: Política externa - pronunciamentos, Brasília: Presidência da República, v. I, De janeiro a junho de 1995, p. 126.

34 Resenha..., $\mathrm{n}^{\circ}$ 76, 1995, p. 19, 89, 118.

35 Resenha..., n $\mathrm{n}^{\circ} 76,1995$, p. 137 e 191.

36 Discurso de Lampreia na reunião de vice-ministros de comércio da ALCA, Recife, 25 fev. 1996: Boletim de integração Latino-Americana, n 19, p. 1-2 (Edições Aduaneiras/MRE)..

37 III Reunião de Ministros responsáveis por Comércio Exterior das Américas, Belo Horizonte, 15 de maio de 1997, discurso do ministro Luiz Felipe Lampreia (originais).

Resumo

Expõe-se o pensamento do governo brasileiro e a política de comércio exterior entre 1930 e os dias presentes. Três constatações da diplomacia brasileira condicionaram o processo decisório: as doutrinas não presidem à prática das grandes potências, um país emergente dispõe de escasso poder nos foros multilaterais, experiências liberais radicais não produzem os efeitos apregoados por seus doutrinários. A política de comércio exterior evitou por essa razão obedecer a grandes princípios e modelos, orientando-se por crescente realismo. Foi historicamente concebida como instrumento de reforço à economia e ao mercado internos e evoluiu com base numa estratégia contraditória que protegia o mercado interno e reivindicava a abertura do mercado global. Cedeu nos anos noventa à tendência da globalização, não sem estender a introspecção para o mercado regional ampliado, o MERCOSUL.

\section{Abstract}

The article exposes the Brazilian government thought and Brazilian external trade policy between 1930 and nowadays. Three verifications of Brazilian Diplomacy have conditioned Brazilian decision-making process: doctrines do not guide the practice of great powers, an emergent country disposes of little power in multilateral fora, radical liberal experiences do not produce the effects proclaimed by their indoctrinators. For this reason, the international trade policy avoided to obey the major principles and models, orienting itself with growing realism. It has been historicaly developed as an instrument to reinforce the internal economy and market, and it has evolved based on a contradictory strategy that protected the internal market and cried out for global markets openning. On the 
90's, it has ceded to globalization tendencies, but not before it had extended introspection to the broaden regional market, Mercosul.

Palavras-chave: Brasil: comércio exterior, desenvolvimento, protecionismo, multilateralismo.

Key words: Brazil: external trade, development, protectionism, multilateralism. 